\title{
Final Report for LDRD Project "A New Era of Research in Aerosol/Cloud/Climate Interactions at LLNL"
}

C. Chuang, D. Bergman, J. Dignon, and P.Connell

January 31, 2002

U.S. Department of Energy

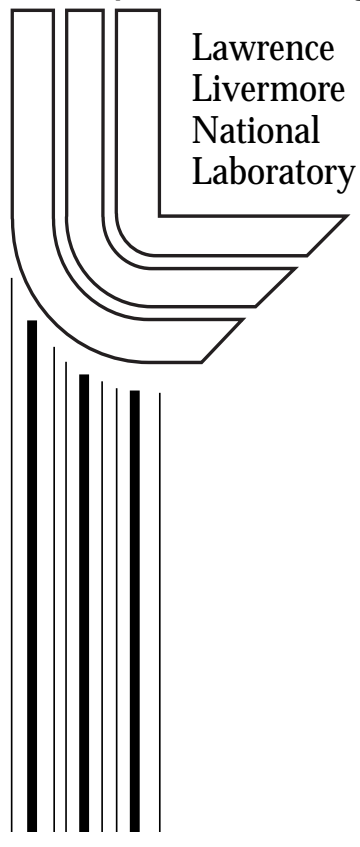




\section{DISCLAIMER}

This document was prepared as an account of work sponsored by an agency of the United States Government. Neither the United States Government nor the University of California nor any of their employees, makes any warranty, express or implied, or assumes any legal liability or responsibility for the accuracy, completeness, or usefulness of any information, apparatus, product, or process disclosed, or represents that its use would not infringe privately owned rights. Reference herein to any specific commercial product, process, or service by trade name, trademark, manufacturer, or otherwise, does not necessarily constitute or imply its endorsement, recommendation, or favoring by the United States Government or the University of California. The views and opinions of authors expressed herein do not necessarily state or reflect those of the United States Government or the University of California, and shall not be used for advertising or product endorsement purposes.

This work was performed under the auspices of the U. S. Department of Energy by the University of California, Lawrence Livermore National Laboratory under Contract No. W-7405-Eng-48.

This report has been reproduced directly from the best available copy.

Available electronically at http://www.doc.gov/bridge

Available for a processing fee to U.S. Department of Energy

And its contractors in paper from

U.S. Department of Energy

Office of Scientific and Technical Information

P.O. Box 62

Oak Ridge, TN 37831-0062

Telephone: (865) 576-8401

Facsimile: (865) 576-5728

E-mail: reports@adonis.osti.gov

Available for the sale to the public from

U.S. Department of Commerce

National Technical Information Service

5285 Port Royal Road

Springfield, VA 22161

Telephone: (800) 553-6847

Facsimile: (703) 605-6900

E-mail: orders@ntis.fedworld.gov

Online ordering: http://www.ntis.gov/ordering.htm

OR

Lawrence Livermore National Laboratory

Technical Information Department's Digital Library

http://www.llnl.gov/tid/Library.html 


\title{
Final Report for LDRD Project "A New Era of Research in Aerosol/Cloud/Climate Interactions at LLNL"
}

\author{
Catherine Chuang, Dan Bergman \\ Jane Dignon, and Peter Connell \\ Atmospheric Science Division \\ Lawrence Livermore National Laboratory
}

\section{Introduction}

Observations of global temperature records seem to show less warming than predictions of global warming brought on by increasing concentrations of $\mathrm{CO}_{2}$ and other greenhouse gases. One of the reasonable explanations for this apparent inconsistency is that the increasing concentrations of anthropogenic aerosols may be partially counteracting the effects of greenhouse gases.

Aerosols can scatter or absorb the solar radiation, directly change the planetary albedo. Aerosols, unlike $\mathrm{CO}_{2}$, may also have a significant indirect effect by serving as cloud condensation nuclei $(\mathrm{CCN})$. Increases in $\mathrm{CCN}$ can result in clouds with more but smaller droplets, enhancing the reflection of solar radiation. Aerosol direct and indirect effects are a strong function of the distributions of all aerosol types and the size distribution of the aerosol in question. However, the large spatial and temporal variabilities in the concentration, chemical characteristics, and size distribution of aerosols have made it difficult to assess the magnitude of aerosol effects on atmospheric radiation. These variabilities in aerosol characteristics as well as their effects on clouds are the leading sources of uncertainty in predicting future climate variation [see Figure 1].

Inventory studies have shown that the present-day anthropogenic emissions contribute more than half of fine particle mass primarily due to sulfate and carbonaceous aerosols derived from fossil fuel combustion and biomass burning. Parts of our earlier studies have been focused on developing an understanding of global sulfate and carbonaceous aerosol abundances and investigating their climate effects [Chuang et al., 1997; Penner et al., 1998]. We have also modeled aerosol optical properties to account for changes in the refractive indices with relative humidity and dry aerosol composition [Grant et al., 1999]. Moreover, we have developed parameterizations of cloud response to aerosol abundance for use in global models to evaluate the importance of aerosol/cloud interactions on climate forcing [Chuang and Penner, 1995]. Our research has been recognized as one of a few studies attempting to quantify the effects of anthropogenic aerosols on climate in the IPCC Third Assessment Report [IPCC, 2001].

Our previous assessments of aerosol climate effects were based on a general circulation model (NCAR CCM1) fully coupled to a global tropospheric chemistry model (GRANTOUR). Both models, however, were developed more than a decade ago. The lack of advanced physics representation and techniques in our current models limits us from further exploring the interrelationship between aerosol, cloud, and climate variation. Our objective is to move to a new era of aerosol/cloud/climate modeling at LLNL by coupling the most advanced chemistry and climate models and by incorporating an aerosol microphysics module. This modeling capability will enable us to identify and analyze the responsible processes in aerosol/cloud/climate interactions and therefore, to improve the level of scientific understanding for aerosol climate effects. This state-of-the-art coupled models will also be used to address the relative importance of anthropogenic and natural emissions in the spatial pattern of aerosol climate forcing in order to assess the potential of human induced climate change. 


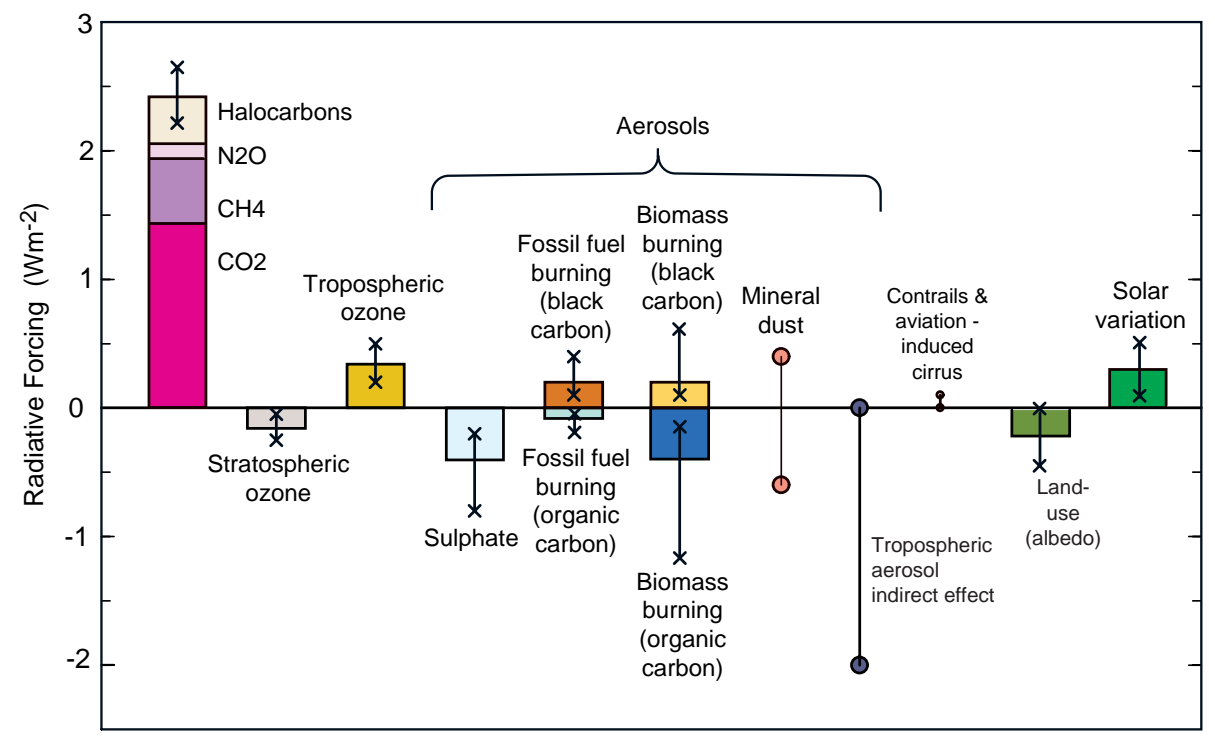

Figure 1. Global, annual-mean radiative forcings due to a number of agents from 1750 to present. The height of the rectangular bar denotes a 'mid-range' value while its absence denotes no best guess estimate is possible. The vertical line indicates an estimate of the uncertainty [IPCC, 2001].

\section{Model development}

The Atmospheric Sciences Division (ASD) has formulated a plan to enhance our modeling expertise in aerosol/cloud/climate interactions. This plan builds on our experience and strength in this area and move into four new areas. First, we added a sulfur chemistry mechanism into the ASD global chemistry model, IMPACT (Integrated Massively Parallel Atmospheric Chemical Transport). Next, we developed an IMPACT aerosol version with a compact sulfur chemistry together with other non-sulfate aerosol species for use in chemistry/climate coupling. Third, we will implement an aerosol microphysics module into the IMPACT aerosol version to include the important processes of aerosol dynamics. Finally, this chemistry-aerosol model will be linked to the most current version of NCAR CCM allowing detailed simulations of cloud cycles.

IMPACT, previously applied to global ozone calculations (version TS2), is an Eulerian global chemistry model that uses advanced techniques to treat the chemical and physical processes. It has been expanded to include the chemistry necessary to simulate the sulfur cycle (version TS3). A new version of IMPACT, version T3A, with compact chemical mechanisms ( 21 prognostic species) and a shortwave radiation package has been developed to study the aerosol climatology. This new version predicts the global distributions of four major aerosol components (sulfate, organic and black carbon, dust, and sea salt) as well as their seasonal variations. By applying the monthly averages of $\mathrm{OH}, \mathrm{HO}_{2}$, and $\mathrm{H}_{2} \mathrm{O}_{2}$ from TS3 simulations ( 100 prognostic species), sulfate is formed through both gaseous and aqueous oxidation from $\mathrm{SO}_{2}$ and DMS (dimethylsulfide) emissions. Other aerosol types, either emitted by nature in the form of particles or formed much more quickly from their gas phase precursors, are assumed to be injected into the global model in the particulate form. This compact version is faster than the full chemistry version by a factor of 10 . We have analyzed the sulfur cycle simulated by TS3 and T3A to explore the effect of non-linearity of certain reaction pathways on the predicted sulfate concentration. A look-up table was incorporated into T3A to take into account such non-linear effect due to the diurnal cycle. We have also compared individual aerosol concentrations with field measurements at different geographical locations to validate the accuracy of the new version.

Since virtually all properties of atmospheric aerosols and clouds depend strongly on aerosol size distribution that are shaped by complicated nucleation, growth, and coagulation processes. These properties underlie the major role of aerosols in radiative forcing of climate. To better represent physical properties of aerosols, we adapted an aerosol microphysics module from the Brookhaven National Laboratory to model the 
spatial and temporal variations of aerosol size distribution. This module simulates the aerosol dynamics via the quadrature method of moments (QMOM) by tracking the moments of an aerosol size distribution in space and time [Wright et al., 2000]. The QMOM offers significant advantages not only for efficiently and correctly incorporating aerosol processes in global models but also for its better representation of aerosol optical properties that are essential to assess the radiative forcing.

We are in the process to couple IMPACT T3A to the most current version of the community climate model (CCM3) developed at NCAR (National Center for Atmospheric Research). CCM3 incorporates an optional slab mixed-layer ocean/thermodynamic sea-ice component able to predict the equilibrium response of climate to externally imposed changes, such as the concentrations of trace gases or the emission rates of various aerosol precursors. The structure of our state-of-the-art coupled models is presented in Figure 2 . The most unique feature of our coupled models is the capability to simulate the variations of aerosol size distribution. This capability will allow us to address the aerosol radiative forcing on a much more solid foundation than previous studies that prescribed aerosol size distributions.

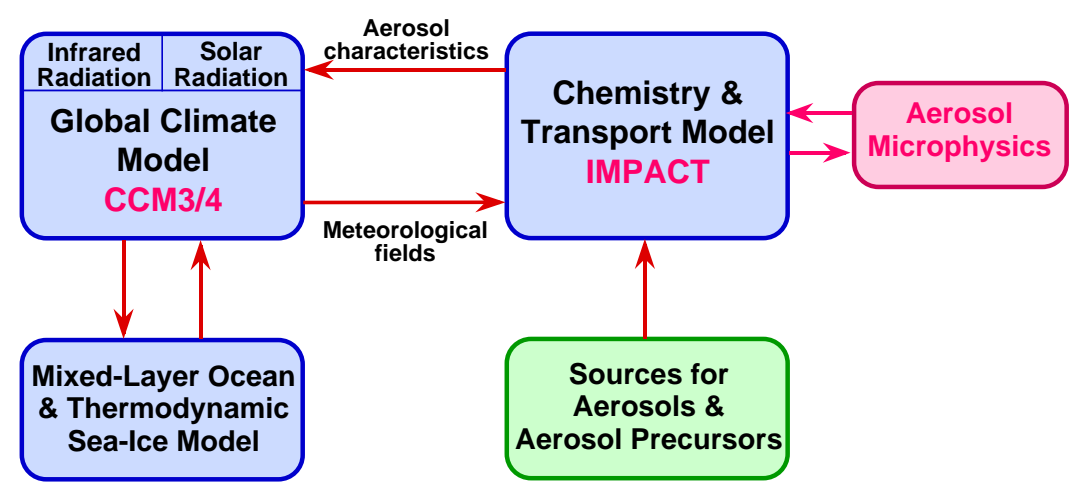

Figure 2. Structure of the state-of-the-art coupled models.

\section{Scientific Progress}

\section{(a) Validation of IMPACT TS3 with in-situ data}

In order to compare to the available data from field measurements, we ran the IMPACT full chemistry version with the assimilated meteorological data for a time period overlapped with the NASA SONEX (SSAS Ozone and Nitrogen Oxide Experiment) project. SONEX project measures the trace species in the upper troposphere and lower stratosphere by flights of DC-8. Figure 3 shows the comparison of model simulated sulfate with those measured from flight number 6 (flight track from Shannon south to $32 \mathrm{~N}$ ) on October 20, 1997. Measurements are presented as 10-minute average and model is in one-hour time step. Dashed line shows the mean of observations along the flight path, and the width of the shaded area represents one standard deviation above and below the mean. While the data exhibit large temporal and spatial variations, the model is able to capture their statistics average. Since IMPACT uses monthly averaged emissions databases and its resolution is large compared to small-scale variability, simulations are incapable of reproducing the high degree of variability along the flight path.
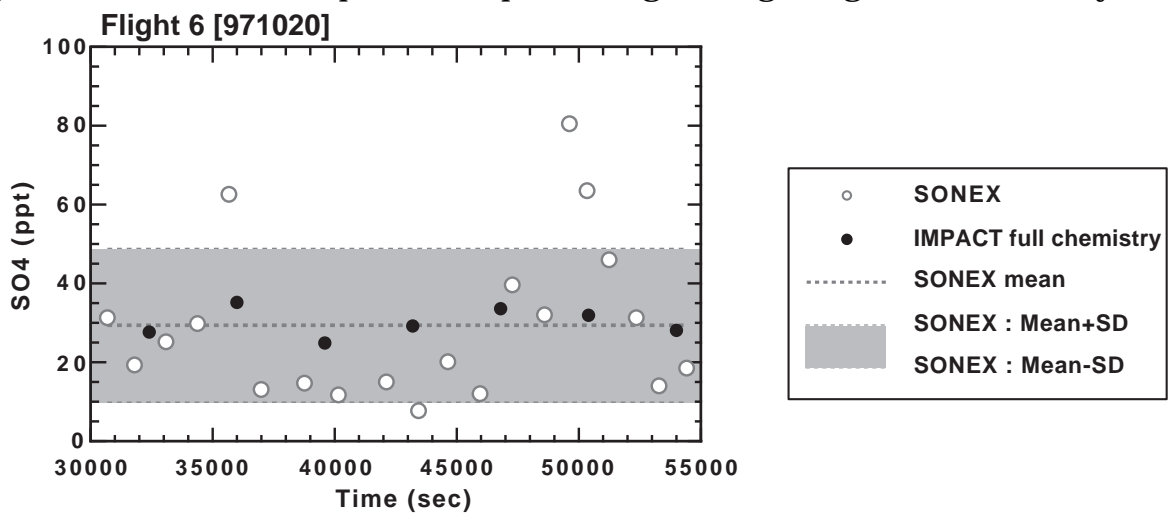
Figure 3. Comparison of the simulated $\mathrm{SO}_{4}{ }^{=}$by IMPACT full chemistry version with those measured from the NASA SONEX project.

\section{(b) Comparison of simulations from IMPACT T3A with TS3}

An efficient but accurate aerosol model is the first requirement to study the aerosol climatology where simulations over 10-40 years are necessary. In Figure 3 we demonstrate that the IMPACT full chemistry version can well represent the statistics of trace species, therefore, we validate the accuracy of the compact version with the full chemistry version. As shown in Figure 4 the maximum regions of simulated $\mathrm{SO}_{2}$ and $\mathrm{SO}_{4}{ }^{=}$ are consistent and the general features are similar in these two versions. This comparison assures that the compact version is not only efficient but also in good agreement with the full chemistry version.
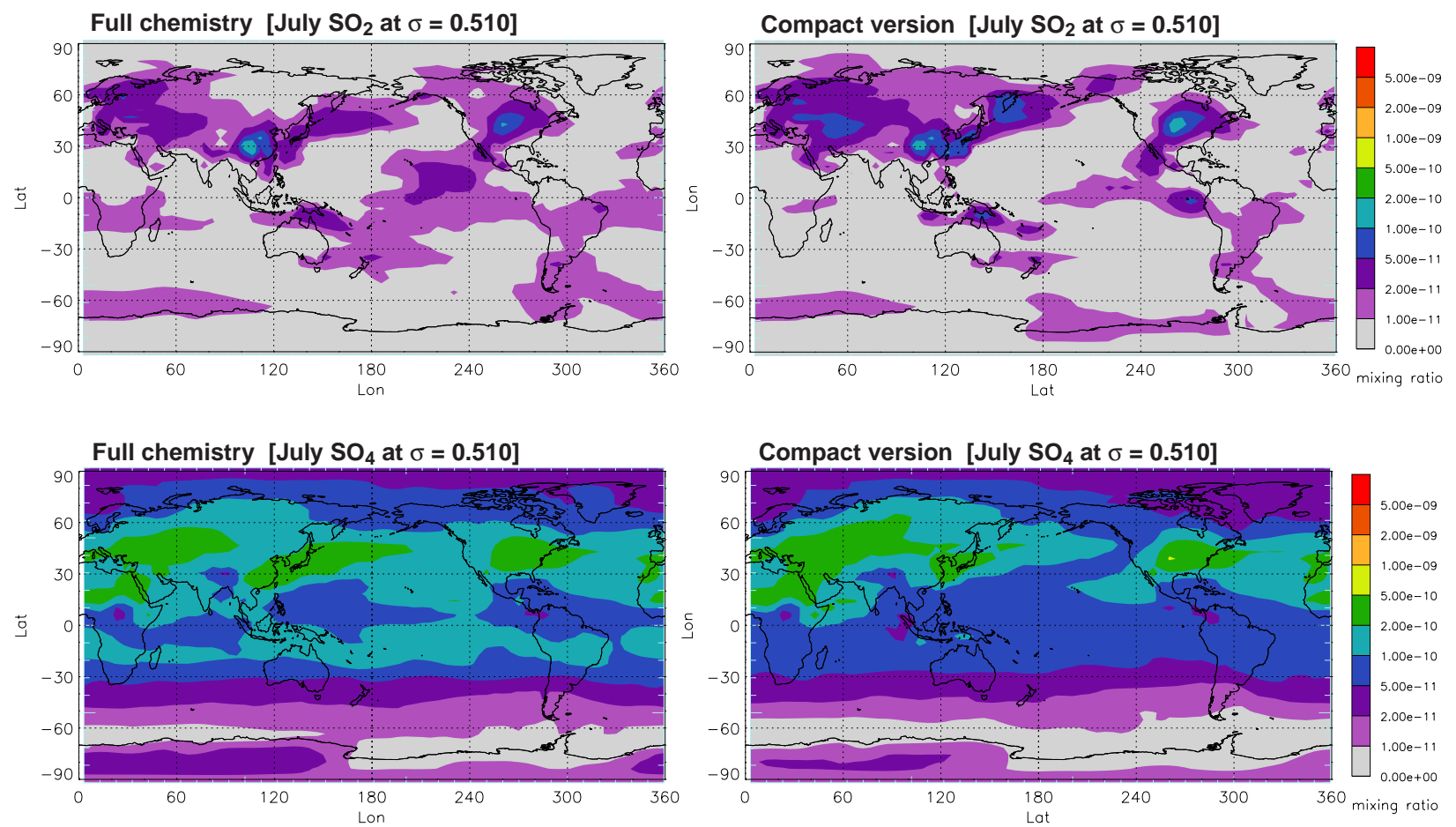

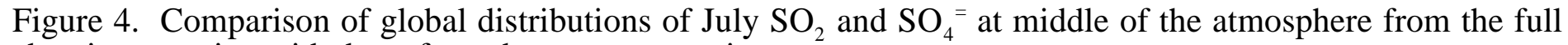
chemistry version with those from the compact version.

\section{(c) Validation of IMPACT T3A with surface measurements}

We compared model results from T3A to surface measurements at a number of remote ocean sites [Prospero, private communication, 2000]. Most measuring sites are located at coastal sites on the climatological windward shore of islands or continental coastlines. The aerosol data are presented at monthly means of at least several years of data and in some cases almost 20 years of data. Comparisons of modelpredicted seasonal surface concentrations of total non-seasalt sulfate and dust are shown in Figures 5 and 6 , respectively. Most of the simulated concentrations are in general within one deviation of the mean of the measurements, but discrepancies do exist such as at the Palmer station. We will examine the ocean source of DMS and the mechanism to convert DMS to sulfate to look for a possible explanation. We also note that the model overestimates winter dust concentrations at the N. Pacific locations. This behavior is associated with the input Asian dust source strength that is a factor of 10 larger in winter compared to spring. 

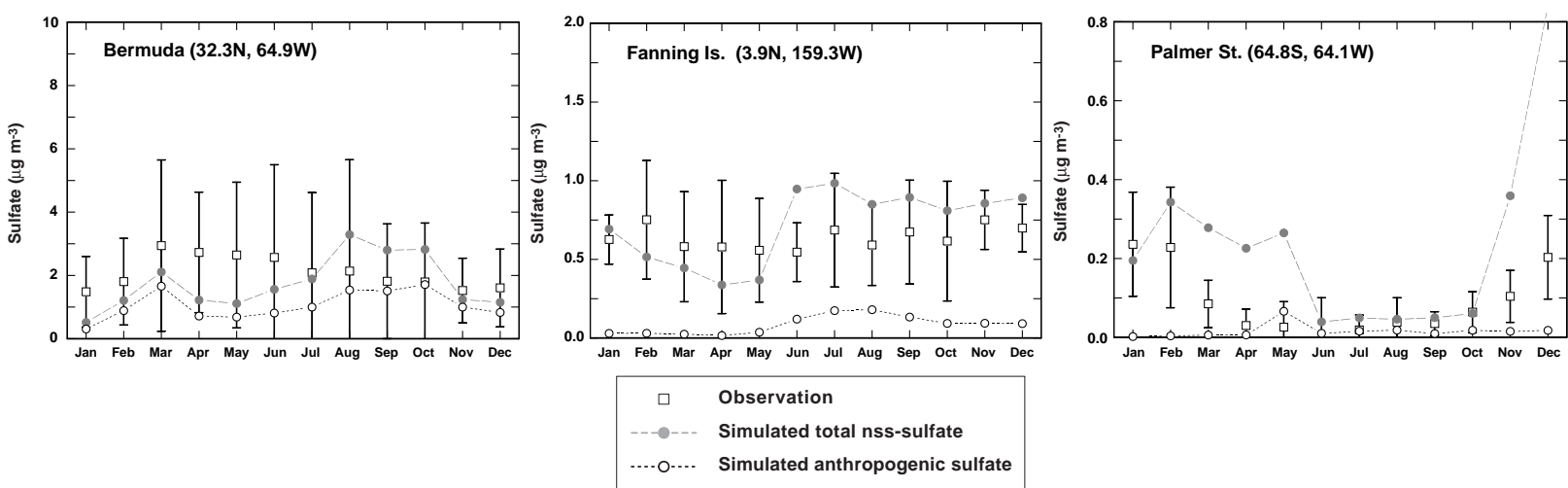

Figure 5. Modeled seasonal surface concentrations of nss-sulfate versus measurements. Error bars are one standard deviation above and below the mean of the measurements.
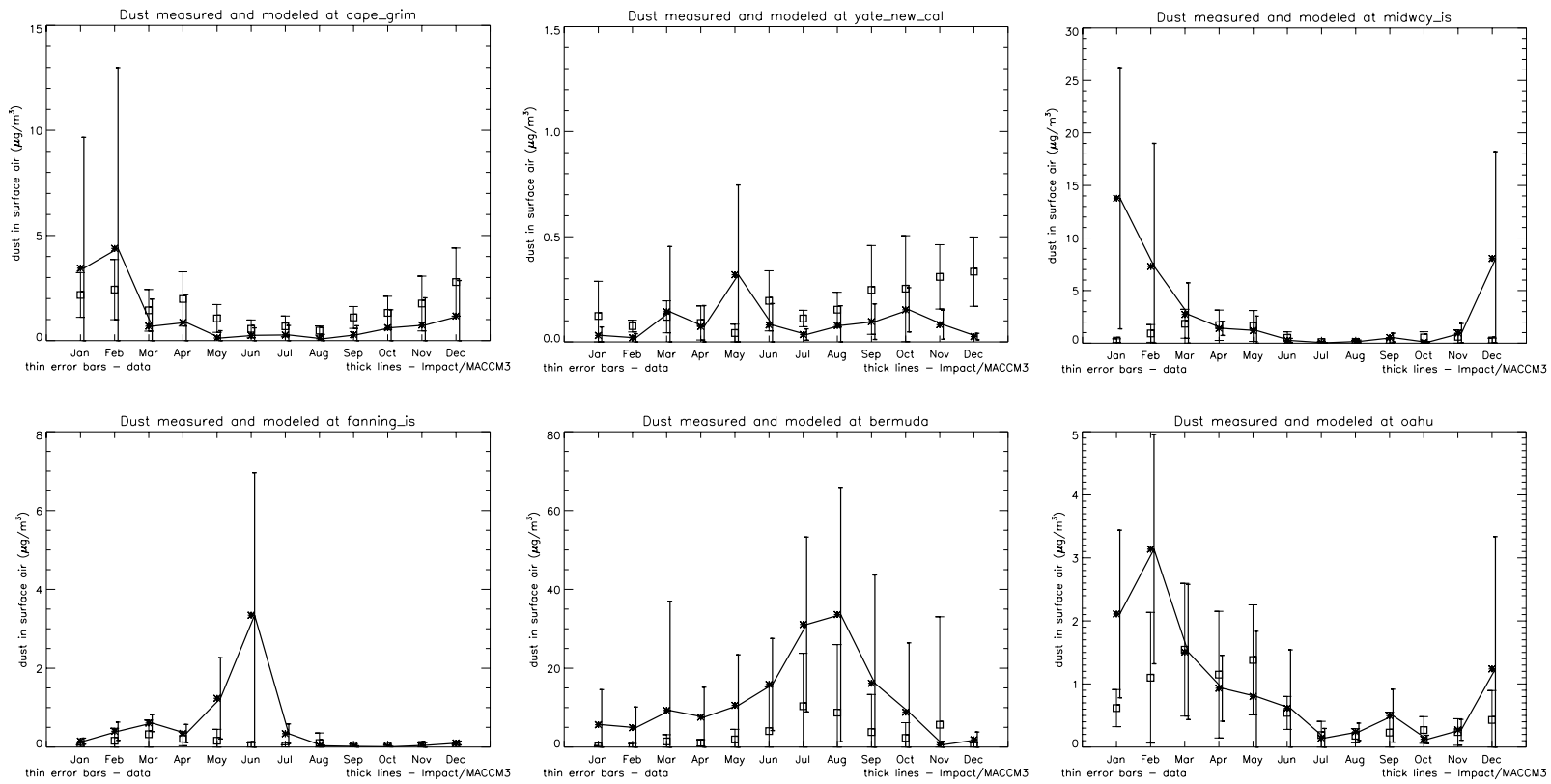

Figure 6. Same as Figure 5 but for dust concentrations.

(d) Evolution of aerosol size distribution moments

The moments of each aerosol population evolve according to the general expression

$$
\frac{\mathrm{d} \mu_{k}}{\mathrm{~d} t}=\left[\frac{\mathrm{d} \mu_{k}}{\mathrm{~d} t}\right]_{\text {source }}+\left[\frac{\mathrm{d} \mu_{k}}{\mathrm{~d} t}\right]_{\text {cond }}+\left[\frac{\mathrm{d} \mu_{k}}{\mathrm{~d} t}\right]_{\text {coag }}+\left[\frac{\mathrm{d} \mu_{k}}{\mathrm{~d} t}\right]_{\text {cloud }}
$$

We put this aerosol module in a box model to gain experience and understanding. Figure 7 illustrates the evolution of moments 0 and 3 in 16 hours for sulfate aerosols with an initial log-normal size distribution $\left(r_{0}=\right.$ $0.01 \mu \mathrm{m}, \sigma=2, \mathrm{~N}=1000 \mathrm{~cm}^{-3}$ ) under processes of nucleation, condensation, coagulation, and dry deposition. The concentrations of $\mathrm{SO}_{2}(\mathrm{~g})$ and $\mathrm{H}_{2} \mathrm{SO}_{4}(\mathrm{~g})$ are set to be $10^{-12} \mathrm{~mol} / \mathrm{cm}^{3}$ and $2 \times 10^{-16} \mathrm{~mol} / \mathrm{cm}^{3}$, respectively. The rate constant for $\mathrm{OH}$ oxidation of $\mathrm{SO}_{2}$ is $6 \times 10^{-7} \mathrm{~s}^{-1}$, and the concentration of sulfate produced in cloud is $10^{-12}$ $\mathrm{mol} / \mathrm{cm}^{3}$. Figure 7 demonstrates that nucleation process increases the aerosol number concentration, whereas coagulation and dry deposition decrease the total number. Although condensation will not change the total number concentration, it is the mainly process responsible for the increase of the total aerosol volume. 


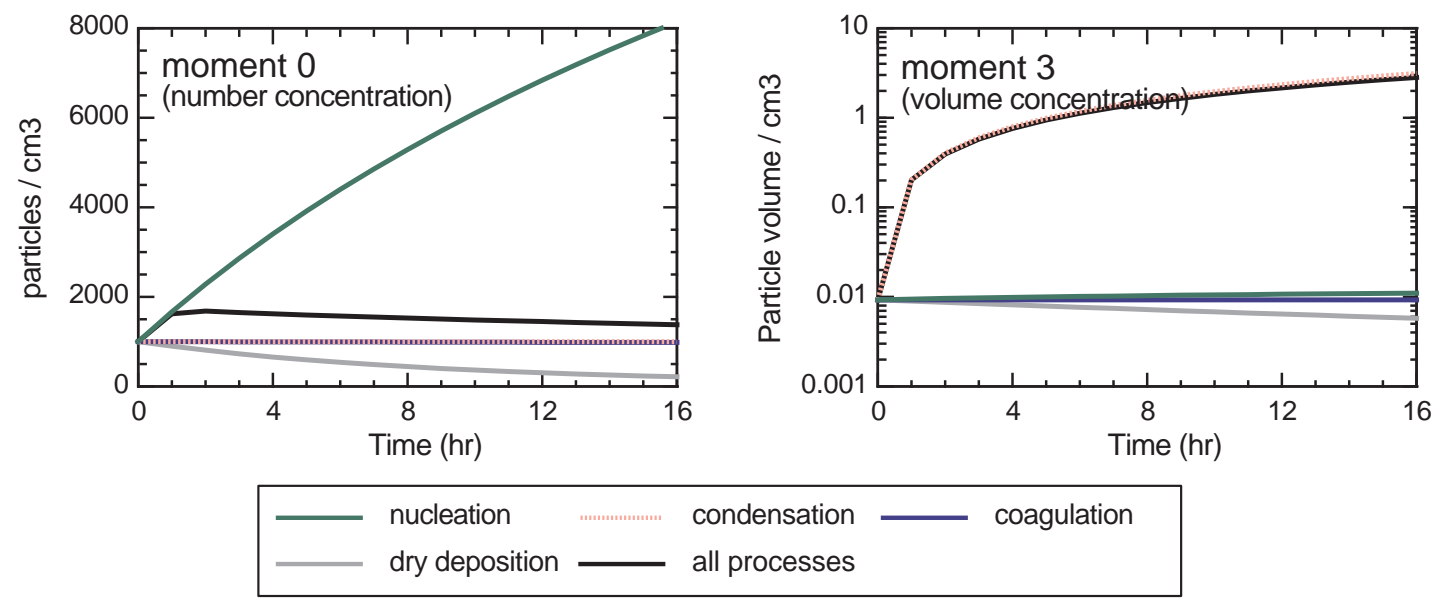

Figure 7. Evolution of aerosol size distribution moments under different dynamic processes.

\section{Future works}

Our simulations have demonstrated that anthropogenic emissions of aerosols and aerosol precursors are large enough to produce significant increases in aerosol abundance in the Northern Hemisphere (see Figure 8). Assessments of the climate impact by anthropogenic aerosols rely on a precise description of aerosol optical properties and an accurate representation of temporal and spatial variations of aerosol distributions. With the fully coupled NCAR CCM/LLNL IMPACT models, we will compare the simulated total aerosol optical depths and extinction profiles to those retrieved from satellite measurements such as NOAA Advanced Very High Resolution Radiometer, and EOS detectors like Moderate Resolution Imaging Spectroradiometer. We are interested in identifying the degree and conditions under which model and the observed aerosols demonstrate significant biases or departures in variability. In regions with significant aerosol extinction, we will characterize the scale of spatial covariance and the effects of such variability on radiative forcing.

It has been noticed that the patterns of climate change in response to anthropogenic aerosols alone and in response to increased levels of $\mathrm{CO}_{2}$ alone can be added linearly to obtain the approximate climate response to the combined forcing due to aerosols and $\mathrm{CO}_{2}$ together [Wigley, 1998]. Therefore, our second goal will be to compare the equilibrium pattern of climate response to the changes that have been detected during the 20-year period of satellite observations. We will examine how the pattern of surface temperature is distinct from the forcing pattern to explore the importance of atmospheric energy transport and the amplification by local feedback.

In order to characterize the future climate variations, we will perform multi-year simulations along with the IPCC newly developed anthropogenic emissions scenarios to estimate the present and future projections of aerosol forcing up to 2100 [IPCC, 2000]. We will investigate the net radiative fluxes by the changes of natural emissions associated with climate change. This work will provide us a more quantitative range for aerosol climate effects as compared to those from greenhouse gases. 

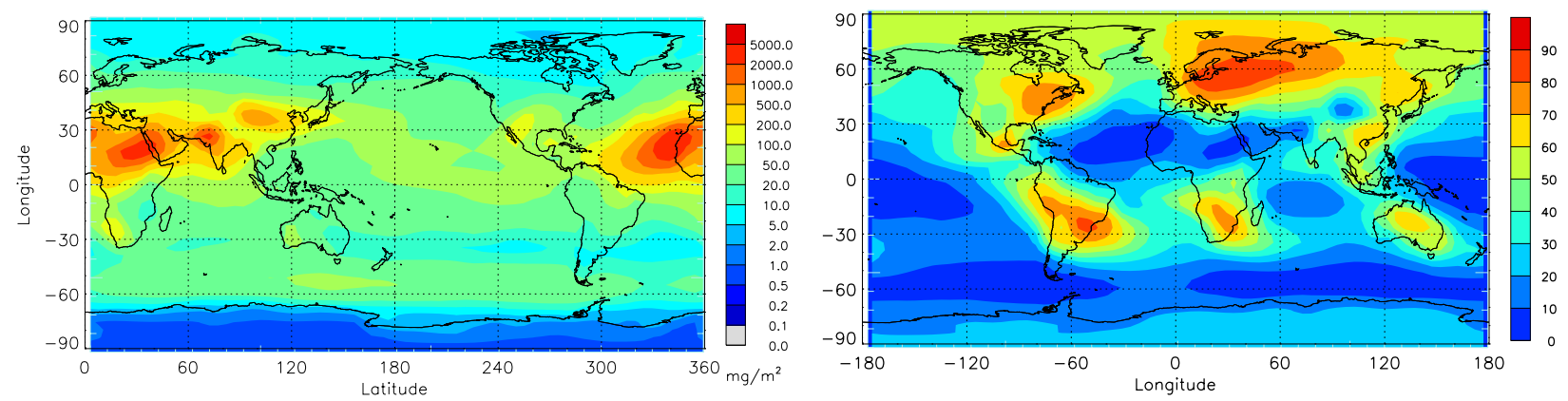

Figure 8. Global distributions of simulated annual-average column abundance of total aerosols $\left(\mathrm{mg} / \mathrm{m}^{2}\right)$ from IMPACT T3A (left panel) and the percentage from anthropogenic sources.

\section{References}

Chuang, C. C., and J. E. Penner, Effects of anthropogenic sulfate on cloud drop nucleation and optical properties, Tellus, 47B, 566-577, 1995.

Chuang, C. C., J. E. Penner, K. E. Taylor, A. S. Grossman, and J. J. Walton, An assessment of the radiative effects of anthropogenic sulfate, J. Geophys. Res., 102, 3761-3778, 1997.

Grant, K. E., C. C. Chuang, A. S. Grossman, and J. E. Penner, Modeling the spectral optical properties of ammonium sulfate and biomass burning aerosols: Parameterization of relative humidity effects and model results, Atmos. Environ., 33, 2603-2620, 1999.

Intergovernmental Panel on Climate Change (IPCC), Special Report on Emissions Scenarios, edited by N. Nakicenovic and B. Swart, Cambridge University Press, 599 p., 2000.

Intergovernmental Panel on Climate Change (IPCC), Climate Change: The Scientific Basis, edited by J. T. Houghton and Y. Ding, Cambridge University Press, 881 p., 2001.

Penner, J. E., C. C. Chuang, and K. E. Grant, Climate forcing by carbonaceous and sulfate aerosols, Clim. Dyn., 14, 839-851, 1998.

Wigley, T. M. L, P. J. Jaumann, B. D. Santer, K. E. Taylor, Relative detectability of greenhouse-gas and aerosol climate change signals, Clim. Dyn., 14, 781-790, 1998.

Wright, D. L., R. McGraw, C. M. Benkovitz, and S. E. Schwartz, Six-moment representation of multiple aerosol populations in a sub-hemispheric chemical transformation model, Geophys. Res. Lett., 27, 967-970, 2000

This work was performed under the auspices of the U. S. Department of Energy by the University of California, Lawrence Livermore National Laboratory under Contract No. W-7405Eng-48. 